\title{
Survey on Molecular Marker and Diagnosis of Helicobacter pylori
}

\section{Bassam Oudh Al johny ${ }^{1}$, Abdulaziz Radhi S ALjohni ${ }^{1,2}$ and Mohamed Morsi M Ahmed ${ }^{\mathbf{1} 3}$}

${ }^{1}$ Department of Biological Science, Faculty of Science, King Abdulaziz University, P O Box 80203, Jeddah 21589, Kingdom of Saudi Arabia.

${ }^{2}$ Department of Laboratory at King Fahad Hospital, Medina, Kingdom of Saudi Arabia ${ }^{3}$ Nucleic Acids Research Department, Genetic Engineering, and Biotechnology Research Institute (GEBRI), Mubarak City for Scientific Research and Technology Applications, Alexandria, Egypt

*Corresponding Author: Bassam Oudh Al Johny, Department of Biological Science, Faculty of Science, King Abdulaziz University, P O Box 80203, Jeddah 21589, Kingdom of Saudi Arabia.

E-mail: boaljohny@kau.edu.sa
Received: March 03, 2020

Published: April 23, 2020

(C) All rights are reserved by Bassam Oudh Al Johny., et al.

\begin{abstract}
This paper will discuss Helicobacter pylori which is a bacterium start in human epithelial cells of the gastrointestinal tract. Its infection is related to many different diseases, such as chronic gastritis, peptic ulcers, gastric lymphoma and adenocarcinoma. The infection by Helicobacter pylori is found more than $50 \%$ of the world. It is found deep in epithelial cells that hide mucus in the human stomach, where neutral Helicobacter pylori are prevalent. This bacterium is reported as the leading cause of various gastrointestinal illnesses, chronic gastritis, excretory ulcer, abdominal cancer and gastric mucosa related lymphoid tissue (MALT) lymphoma. In this study for the improvement of two PCR-based techniques for detecting Helical kinds of Helicobacter pylori. Molecular diagnosis of Helicobacter pylori strain by using $16 \mathrm{~S}$ rDNA PCR amplification and direct examination.
\end{abstract}

Keywords: Molecular Marker; PCR; Gene Diagnosis; Helicobacter pylori

\section{Introduction}

Helicobacter pylori molecular markers

According to previous studies like "Molecular technique for a finding of Helicobacter pylori in clinical samples: an association with the classical diagnostic method" that aimed to detect Helicobacter pylori and to distinguish the diagnostic approaches of the active urease test (RUT) and polymerase chain response (PCR). This study was showed between April and July 2015. For such, three samples were collected from some patients. Two were done for PCR and the other one for RUT.

The results were that some 85 samples were placed from patients experiencing endoscopy, with 56 (65.88\%) females and 29 (34.11\%) males. From the total samples exposed to RUT, 15 (17.64\%) were positive but 70 (82.35\%), negative. In PCR for detection of gene $16 \mathrm{~S}$ ribosomal ribonucleic acid (rRNA) of $\mathrm{He}$ licobacter pylori, 66 (77.64\%) presented positive results and 19 (22.35\%), negative results. According to the analysis that shows the presence of UreA gene in all samples, favorable outcomes were found in 70 (82.35\%) and negative in 15 (17.64\%). According to the results, RUT and the molecular test obtain the statistical difference.

Gastric biopsies from 85 patients were analyzed and found out about 56 (65.88\%) women and 29 (34.11\%) men. Members' ages are varied from 15 to 89 years, with an average of 40.77 years and 27 of the totals $(31.76 \%)$ being 50 years or before. The endoscopic diagnoses provided in the medical reports were: $20(23.52 \%)$ patients with normal inspection, 29 (34.11\%) patients with slight/ moderate esophagitis, 30 (35.29\%) patients with slight/moderate gastritis, three (3.52\%) patients with ulcers and $3.52 \%$ with other diseases. The occurrence of Helicobacter pylori in this study found a molecular method is by studies by Redéen., et al. (2011), assessed 304 individuals and found that one-third had an infection. Also, studies showed by Fox., et al. [1] and Smuts and Lastovica [2] reported that it was possible to observe that PCR diagnosed most of the samples for the detection of Helicobacter pylori in the stomach tissue. According to this study, 85 samples were exposed to the RUT, only 15 (17.64\%) were positive, and 70 (82.35\%) were negative. The high probability of untrue adverse outcomes in the (RUT) is because of the likely reduction in urease activity that may be gained by the recent use of antibiotics, bismuth combinations or proton impel inhibitors, noting that persons who were using these drugs were not accepted. In addition to these factors, the sensitivity of RUT can be affected by the amount and viability of the bacterium present in the biopsy; it is further proposed that specificity decrease with increasing time of incubation, the attention of the test components and the total concentration of urease production. These false-negative results of RUT can also be witnessed when $\mathrm{He}$ licobacter pylori are present in coccid from and urease activity is decreased. Finally, this research assisted that PCR is a beneficial approach inside the laboratory recurring to discover the prevalence of Helicobacter pylori in the stomach tissue, because of excessive compassion and specificity. However, it requires extra analysis and standardization.

Another has a look at turned into under the title, Molecular identification of RNA Gene of Helicobacter pylori mentioned that Mona Mamoun., et al. [3] a total of 81 gastric operations taken from sufferers who had been complaining of gastric disorders in AL Khartoum state, Sudan screened for Helicobacter pylori. Eighteen samples (22.2\%) produced high-quality subculture effects. The majority of them had been men. Also, consequences confirmed the higher prevalence of Helicobacter pylori in patients with gastritis. 
Similarly, identity executed the usage of PCR focused on a place of 16S ribosomal RNA gene of Helicobacter pylori and gene augmented on 12 samples. Six of isolated sequences subjected to an Analysis that showed excessive similarity to GenBank stresses of Helicobacter pylori. More than one collection arrangements have been executed between remoted 16S rRNA gene sequences and maximum related H. pylori races located on GenBank. One isolate differed on one base pair substitution (G-A) from different isolates and decided on reference $H$. pylori traces. Phylogenetic evaluation primarily based on $16 \mathrm{~S}$ rRNA gene sequences reflects that $H$. pylori can come from Africa.

\section{Aim of the Study}

The aim of this study Survey molecular marker and diagnosis of Helicobacter pylori. Molecular diagnosis of Helicobacter pylori strain by using $16 \mathrm{~S}$ rDNA PCR amplification and direct examination.

\section{S rRNA gene of Helicobacter pylori}

This looks at turned into finished in Al-Khartoum kingdom, inside the leading hospitals, such as Khartoum hospitals, Omdurman teaching medical institution, Ibn-Sina health center, and El-Neelien scientific Centre. All of the strategies have been observed out in the countrywide Centre for studies, a branch of Microbiology and central Lab, Departments of Virology and Molecular Biology. The results of this observe said that eighteen biopsies (22.2\%) yielded useful cultures for Helicobacter pylori. The most advantageous cases were $(61 \%)$ were male and elderly between 15 - 30 year. Excellent cultures for Helicobacter pylori about the endoscopy effects differed appreciably as resulted (P fee: zero.036). Out of the18 DNA extracts isolated from gastric biopsies, an area of 16S rRNA gene of Helicobacter pylori as augmented with the aid of PCR in $12(67 \%)$ samples. Collection evaluation showed the id of $\mathrm{He}$ licobacter pylori. BLAST showed ninety-nine \% homology among isolates and revealed diverse accessions of Helicobacter pylori 16s rRNA sequences attained from Genbank.

There was another study in South Africa, Smuts and Lastovica [2] conducted that changed into approximately Molecular Characterization of the 16S rRNA Gene of Helicobacter fennel like isolated from Stools and Blood Cultures. Patients have been in South Africa. It included exceptional thoughts that forty lines of $H$. fennelliae accumulated from pediatric blood and stool samples over 18 years at a kid's hospital in Cape Town, South Africa, were augmented by PCR of the 16S rRNA. The South African H. fennelliae isolates are nearly related to an Australian isolate formerly suggested to be a probable sort of Helicobacter. This study suggests that the former is a strain of $H$. fennelliae. 40 previously characterized traces of $H$. fennelliae were given from pediatric stool and blood samples over an 18 - 12 month's duration. This research shows the admittance to an impressive number of $H$. fenella remoted from Cape metropolis imparting the opportunity to see the genetic sort of those isolates and examine the statistics that to be had in the GenBank database. The $16 \mathrm{~S}$ rRNA and a spread of the RNA polymerase subunit B (rpoB) gene that had been analyzed [2]

The essential effects in this observe became the 16S rRNA of all 40 isolates of $H$. fenella that had been efficaciously amplified, yielding a 1340-bp product. This is larger than the other Helicobacter types because of the presence of H. fenella. Samples confirmed that approximately (52.5\%) of that most of the people had been Campylobacter species. In step with a study for the improvement of two PCR-based techniques for detecting helical kinds of Helicobacter pylori. Infection with Helicobacter pylori happens globally. However, the geographical incidence varies substantially. Better contamination rates appear in developing international locations, where $80 \%$ of center-aged adults are inflamed as compared with infection charges of best 20 to $50 \%$ in devolved nations. Worldwide, the occurrence of Helicobacter pylori contamination increases with age and genuine national companies also are an extra danger. There may be proof that nations with poor purity have more substantial infection prices that shows a conventional water supply as the reservoir instead of a person-to-character transmission. The goal of the studies classified herein become to layout and validate an accurate and sensitive molecular technique for brief detection of both the helical and coccid styles of Helicobacter pylori from culture, medical and environmental samples [4]. Approximately the results, a complete of 26 straining of Helicobacter pylori were tested with the game primers, and PCR effects were useful for all traces tested. DNA became extracted from helical and coccoid types of traces 52185, sixty-one, 33097, and 11637 in spiked water. Different Helicobacter spp. That along with H. mustelae, H. felis, H. pametensis, and $H$. nemestrinae have also been tested. Two species ( $H$. mustelae and H. nemestrinae) were active, and the different species have been no longer useful with the game primers. Helicobacter pylori additionally examined positive in a lab-prepared cocktail that blanketed two lines of E. coli and Vibrio, Bacillus, Salmonella, and Shigella. Suspended in filtered the river water and raised at $15^{\circ} \mathrm{C}$.

However, studies accomplished on animals referred to as "Direct Polymerase Chain reaction check the detection of Helicobacter pylori in humans and Animals showed that earlier rumors of animal infection showed that pylori like organisms had been far away from a pig, a baboon and rhesus monkeys. Although these organisms were morphologically and biochemically just like Helicobacter pylori, conclusive evidence of their identification became lacking. The series facts mentioned right here, the high-quality PCR amplification with $\mathrm{Hpl}-\mathrm{Hp} 2$ and the hybridization with an inside probe are the first-rate proof up to now that the organisms from the pig, the baboon, and the rhesus monkeys were indeed Helicobacter pylori and powerfully advise that those animals obtained their infections from human assets inside the laboratory. Further exam of such a programmer is needed to examine the frequency with that nongnotobiotically reared animals can be inflamed with Helicobacter pylori and used as lab models of this infection. The capacity to hit upon Helicobacter pylori in feces offers the capability for a noninvasive look at for infection and, if fecal detection is showed in $\mathrm{He}$ licobacter pylori -fantastic topics, could lead to big guide for fecaloral unfold because of the predominant mode of transmission. The excessive sensitivity of this exam may be particularly valuable in searching oral bacterial niches and for noticing small numbers of bacteria which could persevere within the stomach after therapy. At the same time as the recrudescence of infection shows the persistence of microorganisms, such bacteria may also continue to be unnoticed with the aid of to be had techniques and supply upward thrust to fake-negative results. Their detection is important because the propagation of residual organisms results in reactivation 
of continuing gastritis and renders the affected person susceptible to ulcer relapse. Hence, the validation of the whole eradication of Helicobacter pylori via the PCR test will be of large fee inpatient management. This looks at found that once all the bacterial DNA, except that from the pig, baboon, and rhesus monkey isolates, became enlarged via the combination of 30 cycles and a strengthening temperature of $55^{\circ} \mathrm{C}$, most straightforward Helicobacter pylori DNA becomes amplified strongly [4].

\section{Molecular diagnosis of Helicobacter pylori}

Concerning Molecular diagnosis of Helicobacter pylori strain by using 16S rDNA PCR amplification and Direct examination. We observed that this have a look at aimed to locate Helicobacter pylori strains by using PCR-Sequencing. It is also used $16 \mathrm{~S}$ rDNA amplification with the aid of PCR from pattern genomic DNA, an affirmation of amplicon length by using agarose gel electrophoresis, sequencing of amplicons by way of the mechanical sequencer, evaluation of sequences by way of NCBI-BLAST software program. Its findings said that the PCR-Sequencing and examination of the collection statistics by way of BLAST resulted in the discovery of the stress to be of Helicobacter pylori pressure. So, A 1. 5kb amplification product became acquired from each of the traces. Partial sequencing of the amplicons changed into executed on a carriedout Biosystems (373A) automated sequencer using the $5^{\prime}$ forward primer. The DNA sequences acquired have been subjected to BLAST seek (NCBI, U.S.A.) for sequence homology and found the excessive percent of homology with 16S rDNA of Helicobacter pylori pressure 26695. The sequences were stated to the GENBANK and had been accepted with rationalization numbers, AY 057935 and AY057936.

The closing looks at was executed under the name "PCR Detection of Colonization through Helicobacter pylori in conventional, Euthymic Mice primarily based at the 16S Ribosomal Gene collection". This look at offered many animal fashions of Helicobacter contamination was categorized, consisting of contamination in rhesus monkeys, ferrets, gnotobiotic piglets and mice. These animal models use a combination of detection methods, including subculture, urease evaluation, and histopathology, all of that can be untrustworthy, insensitive, or labor-intensive. The development of the latest animal models of Helicobacter pylori requires new methods of detection with increased sensitivity and specificity. We have advanced touchy and precise PCR primers primarily based on the 16Sribosomal gene sequence of Helicobacter pylori. Besides, Helicobacter pylori. Human scientific separates of Helicobacter pylori carried out as part of these examinations have been getting from different topographical areas (CL number demonstrates Merck medical way of life amassing) and from the yank kind culture series (Rockville, Md.). Microorganisms were sophisticated on HP medium together with of cerebrum heart mixture agar complemented with $5 \%$ heat-inactivated fetal cow-like serum, $5 \%$ lysed horse blood, $5 \mathrm{mg}$ of amphotericin B (Fungizone; E. R. Squibb, Princeton, N.J.) per liter, $5 \mathrm{mg}$ of polymyxin B (Sigma Chemical Co., St. Louis, Mo.) according to liter, and $5 \mathrm{mg}$ of vancomycin (Sigma). In the beginning, all segregates were evolved in the component way of life, aliquot, and solidified to provide a predict- able supply of comparable section for every separate utilized as a part of all examinations [4].

\section{Treatment}

From these investigations we get a solution for this contamination there are some regimens which are presently acknowledged universally, for the treatment of $H$. pylori ailment in patients with peptic ulcer disease, each belly and duodenal. Those regimens are else known as triple remedies and have announced therapy rates from 85 - 90\%. Tragically, with the mounting ascend in antimicrobial protection there was a related to the growing of the displeasure fee of preferred triple remedy for Helicobacter pylori disorder.

A present record with the aid of researched Smuts and Lastovica [2] reported the viability of a moxifloxacin-containing triple remedy as toa second-line remedy for $H$. pylori pollutants and also the effect of treatment span and anti-infection safety on the annihilation charge In 2004, forty-one patients who had active H. pylori corruption had been given a 7-day direction of $400 \mathrm{mg}$ QD moxifloxacin, $1000 \mathrm{mg}$ provide amoxicillin, and $20 \mathrm{mg}$ provides esomeprazole; the intention-to-treat (ITT) rate became $75.6 \%$ with a for each convention (PP) obliteration rate of $83.80 \%$ and a moxifloxacin protection charge of 5.6\%. Amid 2005 - 2006, 139 patients have been handled to a 10-day route of this regimen, with an ITT charge of $71.9 \%$, PP annihilation fee of eighty- $2.6 \%$ and moxifloxacin safety fee of $12 \%$. One-hundred 8-one patients cured in 2007 - 2008 were given a 14-day triple-treatment recurring: ITT fee, 68\%; PP annihilation fee, $70.9 \%$; moxifloxacin safety rate: $28.2 \%$ [5-23].

\section{Conclusion}

At last, Helicobacter pylori are microscopic organisms that have had a personal association with people for a huge number of years. Notwithstanding the more significant part of the insusceptible reactions, the body uses to endeavor to destroy the bacterium, despite everything it holds on in well more than $50 \%$ of the total populace, frequently tainting kids and multiplying in the stomach covering all through the individual's life. These microorganisms change the causticity of the zones around them to make a positive domain where they can recreate and multiply utilizing proteins and the particles around them in the stomach. Indeed, even with most of our mechanical advances and research dollars spent, regardless we have an extremely constrained comprehension of precisely how these microorganisms associate with the body's guards and can tunnel into the stomach lining and get by there. We have assembled enough data to have a general thought of what happens. However, the points of interest are yet being worked out. That being stated, investigates are working hotly to find more about $\mathrm{C}$ and other microbes and to create cures and antibodies to keep such maladies from consistently happening. It is astonishing how such a small, apparently delicate life form can enter a human and cause such a significant number of issues, from ulcers to gastric malignancies.

\section{Bibliography}

1. Fox JG., et al. "Helicobacter bilis sp. nov., a Novel Helicobacter Species Isolated from Bile, Livers, and Intestines of Aged, Inbred Mice". Journal of Clinical Microbiology (1995): 445-454. 
2. Smuts HEM and Lastovica AJ. "Molecular Characterization of the 16S rRNA Gene of Helicobacter fennelliae Isolated from Stools and Blood Cultures from Paediatric Patients in South Africa". Journal of Pathogens (2011): 217376.

3. Mona Mamoun., et al. "Molecular Identification of 16s Ribosomal RNA Gene of Helicobacter pylori Isolated from Gastric Biopsies in Sudan". American Journal of Microbiological Research 3.2 (2015): 50-54.

4. Traci L Testerman., et al. "Beyond the stomach: An updated view of Helicobacter pylori pathogenesis, diagnosis, and treatment". World Journal of Gastroenterology 20.36 (2014): 12781-12808.

5. Ashtari S., et al. "The prevalence of Helicobacter pylori is decreasing in Iranian patients". Gastroenterology and Hepatology 8 (2015): S23-S29.

6. Brown LM. "Helicobacter pylori: epidemiology and routes of transmission”. Epidemiology 200022 (2000): 283-297.

7. Bui D., et al. "Serologic Evidence for Fecal-Oral Transmission of Helicobacter pylori". The American Journal of Tropical Medicine and Hygiene 94 (2016): 82-88.

8. Covacci A., et al. "Helicobacter pylori virulence and genetic geography”. Science 284 (1999): 1328-1333.

9. Dunn BE., et al. "Helicobacter pylori". Clinical Microbiology Reviews 10 (1997): 720-741.

10. Everhart JE. "Recent developments in the epidemiology of Helicobacter pylori”. Gastroenterology Clinics of North America 29 (2000): 559-579.

11. Falush D., et al. "Traces of human migrations in Helicobacter pylori populations". Science 299 (2003):1582-1585.

12. Garner JA and TL C: "Analysis of genetic diversity in cytotoxinproducing and non-cytotoxin-producing Helicobacter pylori strains". The Journal of Infectious Diseases 172 (1995): 290293.

13. Lacy BE and Rosemore J. "Helicobacter pylori: ulcers and more: the beginning of an era". Journal of Nutrition 131 (2001): 2789S-93S.

14. Lim SH., et al. "Prevalence and risk factors of Helicobacter pylori infection in Korea: a nationwide multicenter study over 13 years". BMC Gastroenterology 13 (2013): 104.

15. Logan RP. "Adherence of Helicobacter pylori”. Alimentary Pharmacology and Therapeutics 10.1 (1996): 3-15.

16. Makola D., et al. "Helicobacter pylori infection and related gastrointestinal diseases". Journal of Clinical Gastroenterology 41 (2007): 548-548.
17. Mégraud F. "Transmission of Helicobacter pylori: fecal-oral versus oral-oral route". Alimentary Pharmacology and Therapeutics 9.2 (1995): 85-91.

18. Midolo $\mathrm{P}$ and Marshall BJ. "Accurate diagnosis of Helicobacter pylori: Urease tests". Gastroenterology Clinics of North America Journal 29 (2000): 871-878.

19. Peleteiro B., et al. "Prevalence of Helicobacter pylori infection worldwide: a systematic review of studies with national coverage". Digestive Diseases and Sciences 59 (2014): 1698-1709.

20. Perry S., et al. "Gastroenteritis and transmission of Helicobacter pylori infection in households". Emerging Infectious Diseases 12 (2006): 1701-1708.

21. Suerbaum S., et al. "Free recombination within Helicobacter pylori". Proceedings of the National Academy of Sciences of the United States of America 95 (1998): 12619-12624.

22. Taylor JM., et al. "Helicobacter pylori lipopolysaccharide promotes a Th1 type immune response in immunized mice". Vaccine 24.23 (2006): 4987-4994.

23. Woodward M., et al. "An investigation into factors associated with Helicobacter pylori infection". Journal of Clinical Epidemiology 53 (2000):175-181.

\section{Assets from publication with us}

- Prompt Acknowledgement after receiving the article

- Thorough Double blinded peer review

- Rapid Publication

- Issue of Publication Certificate

- High visibility of your Published work

Website: https://www.actascientific.com/

Submit Article: https://www.actascientific.com/submission.php Email us: editor@actascientific.com

Contact us: +919182824667 